\title{
Erratum to "Scientific Foundation of Real-Time Input-Output Tabulation Method and AI" [American Journal of Industrial and Business Management 9 (2019) 1831-1872]
}

\author{
-Organic Combinations and Connections between the Optimal \\ Input-Output Planning Model and Automation, Information, \\ Intellectualization, Big Data, New Cloud Computing Technology, \\ Internet of Things or New Internet Industry \& AI Technology
}

\author{
Ning Kang \\ Training and Evaluation Centre, Guizhou Power Grid Company, China Southern Power Grid, Guiyang, China \\ Email: gzkangning@163.com,809716051@qq.com
}

How to cite this paper: Kang, N. (2021) Erratum to "Scientific Foundation of RealTime Input-Output Tabulation Method and AI" [American Journal of Industrial and Business Management 9 (2019) 18311872]. American Journal of Industrial and Business Management, 11, 719-766. https://doi.org/10.4236/ajibm.2021.117047

Received: June 11, 2021

Accepted: July 9, 2021

Published: July 12, 2021

\section{Copyright (C) 2021 by author(s) and} Scientific Research Publishing Inc. This work is licensed under the Creative Commons Attribution International License (CC BY 4.0).

http://creativecommons.org/licenses/by/4.0/ (c) (i) Open Access
The original online version of this article (Kang, N. (2019) Scientific Foundation of Real-Time Input-Output Tabulation and AI. American Journal of Industrial and Business Management, 9, 1831-1872.

https://doi.org/10.4236/ajibm.2019.99119) unfortunately contains some mistakes. The author wishes to correct the errors in the following version:

\section{Abstract}

Be it the era of current Industry 3.0 (3D printing) or the era of Industry 4.0 (customized production) in the future, as far as globalisation is concerned, based on combinations of automation \& information and intelligence, the application of Big Data, new Cloud Computing technology, Internet of Things or new internet industry and AI will usher in a huge revolution to human beings, which will consequently rock foundations of modern economy, politics, social sciences, management and accounting, etc. and even bring about fundamentally changes and development, and hence an era for technology industry will go novelty, i.e. customized production. Commercial re-group and the drastic society change will influence not only the overall ecological pattern around the world but also human beings' value system, knowledge system and life style. Many seeming probabilities today will become impossible while the impossible at the moment will go real in the future. Under such complicated, constantly changing and rapidly developing 
circumstance, only when the passive situation of tabulating and interpreting is completely changed, can national economy's smooth operation be directed by the objective law of coordinated development, and thus, to achieve the utmost economic efficiency. The scientific foundation of the real-time input-output tabulation method and AI is rightly designed on the basis of the above dreaming realization. This thesis will take the real-time analysis of the optimal input-output planning model and the timely analysis of input-output statistical model as examples to illustrate how to realize the good wish.

\section{Keywords}

Big Data, New Cloud Computing Technology, Internet of Things or New Internet Industry, AI (Artificial Intelligence), Auto CAD (Auto Computer Aided Design), CAM (Computer Aided Manufacturing), 3D Printing

\section{1. "One World"}

"One world" refers to an idea that human being will finally realize a beautiful vision of human society in the future. In spite of different description and understanding in politics, economy, culture, science and technology, according to its nature, the foundation of entire human society lies in economy, and that is the starting point and destiny of human society. The economic foundation is related to the entire society and it is a great support which backs up nations for the strong competitiveness; thus how to make this foundation (economy) be systematically managed and regulated as well as maintained in the best operation? Obviously, the real-time analysis of the optimal planning input-output model and the timely analysis of the input-output statistical model become the key technology. Therefore, other problems will be solved as long as that critical problem can be properly dealt with.

It is known that ecology or ecological environment refers to the general environment or situation of human society, which mainly includes two aspects, good thinking ability, analytical and critical spirit and truth seeking hobby as well as philosophical tradition. Philosophical tradition refers to the profound influence on human thinking, which not only provides tools, but also determines area and direction. The process of Internet of Things or new internet industry, mobile interconnection, interconnection of everything and ecological interconnection will give birth to a new economic system, which is called interconnection and shared economy; the process of mobile interconnection, etc. will also give birth to a new economic system called interconnected communist economy; the development of the process of Internet of Things or new internet industry, mobile interconnection, etc. is only the starting point of shared economy and communist economy. Therefore, their emergence and rapid development have brought mankind into a linkage era or an iteration era. This era of interaction and iteration has only one goal which is to build a new economic system-shared economy and to 
create a new society-shared society. It can be seen that the interconnected shared economy and the linkage communist economy constructed through the new economic system create the theoretical basis of one world. The shared society based on the new society is the long-awaited one world. It is obvious that if the basic content of the modernization enterprise management on a micro-level and its approach, "Nine-Must"-Production Pioneer of Linear Model in Enterprise Modern Management can be taken to observe, test and judge whether in one world, the enterprise management has realized the characteristics, scale and standard of modern management; if the basic content of the cross-boundary economic management information system on a macro-level can be taken to observe, test and judge the characteristics, scale and standard of the technology support for all the nations to re-build the new economic order in one world. Thus, to realize the unification of economic base and superstructure, fair trade and free competition, economic interests and value pursuit by rebuilding the final result of the new economic order of the world is not only the theoretical basis of global economic governance in one world, but also the scientific method of establishing a new international economic order and creating a new human civilization.

For realizing "one world", regardless of social form or system, as long as the real-time analysis of the optimal input-output planning model and the timely analysis of the input-output statistical model shall be implemented, the unification of economic foundation and superstructure, fair trade and free competition, economic benefit and value pursuit can be realized. It is very important to make this point clear.

\section{The Scientific Basis of Real-Time Input-Output Tabulation Method and AI}

Regardless of 3D printing (Industry 3.0) or customized production (Industry 4.0), in AI unmanned factories, all work can be done by computer-controlled robots, CNC machine tools, unmanned trolleys and automated warehouses. Instead of working directly, workers become commanders and doctors. During daytime, a small number of workers can handle the work such as order checking and modifying; at nights, even fewer workers are left to monitor. The precise process is summarised as following.

\subsection{Background}

Based on "All economic activities of International Standard Industrial Classification" (ISIC) published by United Nations Bureau of Statistics which provides standard criteria of statistical data for different countries to compare and the division of industrial sectors, agriculture belongs to the primary industry, industry belongs to the secondary industry and others belong to the tertiary industry. In the primary industry, products can be obtained directly from nature through human labor, including agriculture, forestry, animal husbandry and fishery; in 
the secondary industry, the products (raw materials) provided by the primary industry and the secondary industry itself are processed. According to the accounting budget (plan) and the degree of difficulty in accounting, the departments which are engaged in product structure (components) and bill of materials (food, medicine and chemical industry which is referred as BOM, hereinafter the same) are named manufacturing; the departments which are engaged in extractive industry, construction, public works, water, electricity, oil and gas are called other industries; the tertiary industry is the sector other than the primary and the secondary that provide only final services to consumers and intermediate services to producers (including producers of the tertiary industry itself), including transportation, storage and postal service, information transmission, computer service and software, wholesale and retail, accommodation and catering, finance, real estate, leasing and business service, scientific research, technology service and geological exploration, water conservancy, environmental and public facilities management service, residential service and other services, education, health, social security and social welfare, culture, sports and entertainment, public administration and social or international organisations. For convenience, those that make profit are categorised as service industry while those do not are categorised as non-profit organisations. The basic relation of the three major industries is to regulate yet to rely on each other. The primary lays the foundation for the secondary and the tertiary; the secondary is the core of the three industries and it brings along the primary; the primary and the secondary create opportunities for the tertiary; the development of the tertiary boosts the primary and the secondary.

According to the basic method of input-output statistical tabulation method all over the world, it can be seen that because of different accounting systems, the basic structure of the model is also different. For example, by applying SNA (The System of National Accounts) as the accounting method, production and labor supply are included in the form of production and the monetary income from production factors is included in the national income. By applying MPS (The System of Material Product Balances), the national economic activity can be divided into material production field and non-material production field, and only the material production field is considered the part of the production and included in the national income. Because theoretical basis, research field and basic flow of these two kinds of accounting systems are different, their basic structure of the input-output statistical model is also different. In addition, there is only value-based input-output model in SNA. However, in MPS, both value-based input-output model and material-based input-output model exist. In order to solve the problem of the comparability of statistical data among different countries, the conversion of aggregate index can be carried out according to the difference of those two accounting systems. For example, the conversion between national income and added value, between total social products and material consumption along with total output and intermediate input, between 
personal consumption and household consumption, and between other corresponding indicators. The comparability can be accordingly realised (Dong, 2000).

According to the basic theory put forward by John McCarthy (the inventor of $\mathrm{AI}), \mathrm{AI}$ is about the science and engineering of making intelligent machines, and in particular, the programme of creating artificial intelligence. After being programmed, the computer is able to think like human. Through the research of human brain and its capability of study and work, for instance, the result becomes the foundation of the development of intelligent software and system. AI is different from human intelligence. However, it has the ability to imitate and probably exceed human intelligence one day. AI is a branch of computer science that attempts to understand the essence of intelligence and build the intelligent machine that can respond in a similar way to human intelligence. In general, one of the main goals of AI research is to enable machines to perform complex tasks that usually require human intelligence. It must be pointed out that different people of different time have various understanding of such kind of complex tasks. Therefore, as the science, the specific goal of AI will naturally be evolved according to changes from time to time. Since its birth, the theory and technology of AI have been getting more and more matured, and its application has been expanding. It can be seen that in the future, the technological products brought along by AI will become a container of human intelligence. On the one hand, it continues to make new progress, on the other hand, it starts to set goals that will be more meaningful though more difficult (Cai \& Xu, 2010).

In terms of the ability of problem solving, AI can be divided into three categories, weak AI, strong AI and super AI. As weak AI, ANI (Artificial Narrow Intelligence) is good enough for individual use, for example, smart bikes and cars. According to Professor Linda Gottfredson, AGI (Artificial General Intelligence) is "a comprehensively psychological ability regarding thinking, planning, problem solving (sometime even abstract issues and complex ideas), fast learning and learning based on experiences". As strong AI, AGI is at human-level because it can be considered equal to human intelligence and used for doing everything that requires human intelligence. Creating AGI is much more difficult than creating ANI, so far, it is beyond human's capability. ASI (Artificial Super Intelligence) is defined by Professor Nick Bostrom (Oxford philosopher and thinker) as "intelligence that is much smarter than the smartest human in all fields such as scientific innovation, general knowledge and social skills". In terms of ASI, no matter it can be either a little stronger or much stronger than human intelligence, it has been brought to public sight and that is why these two words-immortality and extinction, have been paid close attention to.

According to the basic concept of computer network, it is built up with interchangeable and programmable hardware. However, hardware is not specifically used for any certain purpose (transmission of data or video signal). They can be used to transmit a variety of different types of data, and support a wide range of growing applications. According to this concept, the hardware connected to a 
computer network is not limited as ordinary computers, but as smartphones, too; computer network is not specifically designed for data transmission, but for the support of a variety of applications (including the applications which will be used in the future). "The programmable hardware" here means that it must be CPU (Central Processor Unit) involved (Xie, 2017). It is obvious that the communication between computers can be realised through the interconnection, so that functions such as information, software and equipment resources sharing, and the ability of working together in computer systems can be greatly realised as well. Computer resources include computer hardware, software and data. Computer network can provide network services to both local and remote users; all computers in this network abide by a network protocol. Computer network architecture which is to unify the protocol around the world establishes software and hardware standards, and precisely defines the functions that the computer network and its components should perform. Therefore, different computers can do information docking with the same function. Computer network is based on a highly structured design method and applying the principle of functional stratification. In addition, regarding the range of action, network can be divided into four different types, PAN (Personal Area Network), LAN (Local Area Network), MAN (Metropolitan Area Network) and WAN (Wide Area Network). However, WAN is the core part of internet. Its main task is to transport the data which is sent by mainframes over long distances (across countries), and the link that connects the switches of all connecting points is generally high-speed link which has a large communication capacity.

According to the basic principle of Auto CAD (Auto Computer Aided Design), it is known that Auto CAD software was first developed by Autodesk Company in 1982 which is useful for designers to carry out their work by using computers and the graphics devices. Auto CAD software can be run on micro-computers and work-stations which are supported by various operating systems. It can be used in two-dimensional drawing, detailed drawing, designed documents and basic three-dimensional design; it provides a good user interface which is able to carry out various operations through interactive menus or command-lines. In the process of engineering design and product design, different schemes can be calculated, analyzed and compared in order to determine the optimal schemes. All kinds of design information, such as digital, text or graphics, can be stored in computer memories or external storage and quickly retrieved. Designers usually start the work from sketches, then the heavy work for turning the sketches into engineering drawing can be done by computers. The engineering drawing is automatically established by computers which can be quickly displayed afterwards, so that designers will be able to judge and modify the work in time. Auto CAD application area includes engineering drawing, architectural engineering, decorative design, environmental art design, hydro-power engineering and civil construction, etc., which has become the popular tool worldwide. 
According to the basic principle of CAM (Computer Aided Manufacturing), it is known that CAM software was first developed by Massachusetts Institute of Technology in 1952. It can be used to complete the entire production process from preparation to manufacturing with computer assistance. CAM software is able to directly or indirectly connect computers to manufacturing process and production equipment. With computer system, it is applied to plan and manage manufacturing process, control and operate production equipment, process data which is needed in the manufacturing, control and process flow of materials (semi-finished products and components), as well as test and check finished products, etc. The core technology of CAM is numerical control (short for Computer Numerical Control) which is to generate NC code that machine tools can read by computer programming, so that the machine tools will be able to run more accurately and more efficiently for less cost.

According to the definition of basic functions of 3D printers which was put forward by two Americans, Professor Hod Lipson and Professor Melba Kurman, " $3 \mathrm{D}$ printing is an opening. A revolution of manufacturing, design, material and intellectual property is about to be detonated by $3 \mathrm{D}$ printing and its great prospect will be unfolded. By crossing the gap between virtual world and real world, the iron law of scale economies is broken. $3 \mathrm{D}$ printing will bring $\mathrm{AI}$ from computers to elsewhere, the robot time will become history and an outbreak of revolution in science, technology and innovation will eventually take place." The advantage of $3 \mathrm{D}$ printing is to bring models which are not only visible, but touchable as well; it transforms not only creative ideas of designers in forms of in-kind, but avoids disappointing objects occurring from qualified designs. Since the objects made by 3D printing can be assembled, and the rationality of structure and the feasibility of installation can be intuitively observed, the possible problems thus can be revealed and solved in early phases. The cost of traditional manufacturing of moulds is generally high and the large ones can be extremely expensive, therefore, in case of product structures appearing unreasonable or other problems occurring in the process of mould making, the loss can be huge. With 3D printing, not only can the loss be avoided, but certain risks as well. 3D printers integrate advanced technologies, such as digital modelling technology, electromechanical control technology, information technology as well as material science and chemistry. Therefore, machines can be not only designed, manufactured, repaired and recycled by other machines, but adjusted and improved as well, sometimes even by themselves (Lipson \& Kueman, 2013). The rapid prototyping technology of 3D printing has been widely used in design and development of automobile, machinery, aerospace, household appliances, communication, electronics, architecture, medicine and toys, and this is very helpful to the establishment of optimal micro material-based input-output planning model.

\subsection{Scientific Foundation of AI}

As it is known, AI (Artificial Intelligence) is the new science and technology aiming at research and development of theories, methods, technologies and ap- 
plication systems for simulating, extending and expanding human intelligence. According to the scientific thought, theory and method of real-time input-output tabulation method, in order to actualize the real-time analysis of the optimal input-output planning model and the timely analysis of input-output statistical model, the real-time input-output tabulation method and the scientific basis of AI can be summarized and described as theoretical, material and technological basis of AI (same as below).

Theoretical basis of AI mainly constitutes theories of Big data intelligence, cross-media perceptual computing, mixed enhanced intelligence, collective intelligence, decision making in autonomous cooperative control and optimization, brain-like intelligent computing, quantum intelligent computing. The core technologies of AI are computer vision, machine learning, natural language processing, robot and speech recognition, all of which will become independent sub-industries. In terms of the core technologies of AI, computer vision is the computer ability of recognizing objects, scenes and activities from images; machine learning is the ability of computer systems for improving the performance without following explicit program instructions but relying only on data; natural language processing is the ability of having human-like text processing; robot means the ability of integrating cognition technologies such as machine vision and automatic planning into minimal size but high-performance sensors, brakes, and ingenious hardware, which is able to work with humans and handle different tasks flexibly in various unknown environments; speech recognition mainly focuses on automatic and accurate transcription of human speech technology.

The theoretical basis and the core technology mentioned above are the very basis and technology of real-time input-output tabulation method and the scientific basis of AI. In addition, with the organic combination and development between automation and information technology, the status of continuous mathematics as a mainstream which is represented by calculus has changed in the era of industrial revolution, and the importance of discrete mathematics has been gradually recognized. Being the theoretical basis of computer science, discrete mathematics widely demonstrates in many fields of computer science and technology and related specialities. For example, from scientific computing to information processing, from theoretical computer science to computer application technology, from computer software to computer hardware, from AI to cognition system, etc., all are closely related to discrete mathematics. And for the scientific thought, theory and method of real-time input-output tabulation method, discrete mathematics is certainly involved and being the reasons why, 1) the optimal input-output planning model can be realized by combining with automation, information, intelligence, Big data, new Cloud Computing technology, Internet of Things or new internet industry and AI; 2) the organic combination and connection between the optimal micro material-based input-output planning model and industrial software, such as Enterprise Resource Planning (ERP), Auto Computer Aided Design (Auto CAD), Computer Aided Manufac- 
turing (CAM), Computer Integrated Manufacturing (CIM) and 3D printing can be actualized; 3) the real-time analysis of the optimal input-output planning model and the timely analysis of input-output statistical model, and so on.

The material basis of AI is based on realizing intensive modernization (automation, information and intellectualization, same as below) of the three major industries. According to the basic structure of the optimal macro input-output planning model, with interconnections among the system of computer networks (Internet of Things or internet), the formation of the material basis includes two contents, 1) according to the basic structure of the optimal micro input-output planning model, the affiliated industries (sections or products) of the three major industries and their objects can be formed into small individual systems, and these small systems are the material basis of the corresponding micro cross-boundary economic management information system; 2) according to the basic structure of the optimal macro input-output planning model, not only can those small systems be formed into independent subsystems according to hierarchies of industries, those subsystems can also be formed into an independent large-scale system. That independent large-scale system is the material basis of the "cross-boundary economic management information system" (Kang, 2019).

Based on realizing the material basis of AI, the technology basis of $\mathrm{AI}$ is, 1) on the one hand, according to the characteristics and specialities of the affiliates of the three major industries and their objects to design and develop the cross-boundary economic management information system; 2) on the other hand, to vertically start from the basic data processing to the basic data which is required for the realization of real-time analysis of the micro input-output model and timely analysis of input-output statistical model with computer technology, according to the theory and method of input-output planning model as well as some certain steps and computations to respectively establish database files which are based on the basic data. Those database files will be the strong foundation in the future for applying AI to solve the problems of table making and its application.

\subsection{Scientific Foundation of the Optimal Micro Input-Output}

The reason why real-time input-output tabulation method can realize the real-time analysis of the optimal input-output planning model and timely analysis of the input-output statistical model, the scientific method found which is for the realization of the real-time analysis of the optimal micro material-based input-output planning model with data required as well as the timely analysis of the micro material-based input-output statistical model. Without that breakthrough, nothing can be achieved. According to the inherent connection and difference between the optimal micro material-based input-output planning model and the micro material-based input-output statistical model (Kang, 2014a), it is known, 1) since the micro material-based input-output statistical model is built based on the real-time analysis of the optimal micro materi- 
al-based input-output planning model, in terms of basic data, apart from which of internal flow matrix, final products and total output that remains the same, it is different for the variety and quantity of the purchased products as well as the corresponding physical volume which are input by each section in each process. Because it can be both stats value and plan value. Therefore, as long as the database files that should be based on what kind of basic data for realizing the real-time analysis of the optimal micro material-based input-output planning model becoming clear, the problems such as realization of the timely analysis of the micro material-based input-output statistical model as well as the method of establishing the database files based on basic data while realizing the real-time analysis of the optimal macro input-output planning model and the macro input-output statistical model will be solved. In the three major industries, the method of applying AI for establishing the optimal micro material-based input-output planning model is the key. The final product manufacturing (components and $\mathrm{BOM}$ ) is taken as an example for the better explanation. For the convenience, there is no reverse consumption in the internal flow matrix of the optimal micro material-based input-output planning model, but the forward consumption which is direct and standardized. The explanations are as followings.

According to the tabulation method of realizing the real-time analysis of the optimal micro material-based input-output planning model (Kang, 2014a), for skilled technicians engaged in production-operation-plan, once the variety and quantity of final products and the corresponding physical volume are determined, through the manufacturing process starting from input and withdrawing from the production cycle, the variety and quantity as well as its volume of every process of input (consumption) and output can be calculated through the technical manual of product standard; during each process of semi-finished products, the variety and quantity of those products and the corresponding physical volume as well as the variety and quantity of the purchased products and the corresponding physical volume that need to be input (consumed) in each process can also be calculated by consumption quota or man-hour quota. According to the balance (semi-finished products + final products = total output, same as below) established in rows, the total output of each production can be calculated. Thus, the above data is the basic data needed for establishing the micro material-based inout-output planning model. And with the establishment of the model, by combining with linear programming method, the optimal scheme of product structure can be laid down with limited resources, such as investment and labor force. It can be seen that according to the scientific thought, theory and method of real-time input-output tabulation method, manually establishing the optimal micro material-based input-output planning model is not only easy and feasible, but promoted and generalized.

For ANI, in order to use computer technology to establish the optimal micro material-based input-output planning model, first of all, the steps and calcula- 
tion method of manual tabulation should be clear, and the data base based on basic data will be respectively established. For example, to establish the data base based on the basic data of product structure (components) or bill of materials (formula) of final products and between the relevant processes of processing routes. The data base should include name, specification, model, quantity and other basic information of final products as well as the same information of semi-finished products in each process. With the data base, 1) the variety and quantity of final products can be modified according to market demand as well as name, specification, model, quantity and other basic information of semi-finished products. 2) According to the variety and quantity of the input and output and the physical volume as well as corresponding name, specification, model, quantity and other basic information in each process, with the corresponding data base based on technical parameter of product standard, the variety and quantity of input and output and the physical volume in each process can be respectively calculated. It must be pointed out, the basic data of the internal flow matrix in the general micro material-base input-output model appears to be upper triangular in non-zero elements, that is, the non-zero elements are in the upper right half of the main diagonal. In order to find scientific methods of writing computer applications (algorithms), it is necessary to introduce the internal flow input matrix and the internal flow output matrix respectively, and the variety and quantity of both input and output as well as the corresponding physical volume in each process can be represented by the above matrices. Therefore, by dividing the variety and quantity of the relevant non-zero elements in the internal flow input matrix by the variety and quantity of the relevant non-zero elements in the internal flow output matrix, the internal flow matrix with a ratio which is always $>1$ (for some special processes, a ratio can be equal to zero if the data disparity between the two matrices is negligible) structured and formed in the exactly same way can be obtained. It is obvious that the ratio of the variety and quantity of non-zero elements and the corresponding physical volume of this internal flow matrix is actually the ratio of the variety and quantity and the corresponding physical volume of input and the variety and quantity and the corresponding physical volume of output in each process. By applying the ratio, starting from the final products, from top to bottom and right to left, calculating one by one forward until the input of the first process, the basic data of non-zero elements in the internal flow matrix can be calculated through a specific computer application (algorithm). In the process of calculation, according to the basic principle which is the variety and quantity of output and the corresponding physical volume in the previous process becoming the variety and quantity of input and the corresponding physical volume in the following process; if the variety and quantity of the input and output are equal, it means that only the form of products is changed but the structure, and the variety and quantity of input and the corresponding physical volume can be obtained by multiplying the variety and quantity of output and the corresponding 
physical volume by the ratio; if the variety and quantity differ between input and output, it means both the form and structure are changed, and the variety and quantity of input and the corresponding physical volume in current process can be obtained by multiplying the variety and quantity of output and the corresponding physical volume by the ratio and this result should be the summation of the variety and quantity of total input and the corresponding physical volume. In other words, in this very process, except the variety and quantity of output and the corresponding physical volume in the previous process, the variety and quantity of input and the corresponding physical volume in current process are included. According to the data base based on consumption quota or man-hour quota and other basic data during the manufacturing semi-finished products, not only the variety and quantity of purchased products and the corresponding physical volume that need to be input (consumed) in each process can be calculated, but the name, plan, model, quantity, suppliers and other basic information of the purchased products can be shown as well. According to the balance established in rows, the total output of each production can be calculated. The above data above is the basic data for the micro material-based input-output planning model. 3) Therefore, according to the data base based on the basic data of the model and the basic information needed by the mathematical model which is combined with the linear programming method, the optimal product structure scheme can be laid out with establishing the optimal micro material-based input-output planning model. Thus, according to the scientific thought, theory and method of real-time input-output tabulation method, by programming with human's logic and knowledge, it is not difficult to use ANI to establish the optimal micro material-based input-output planning model. And it is the key to actualize the real-time analysis of the optimal micro material-based input-output planning model.

It must be pointed out that, 1) with the change of market demand, the adjustment and modification need to be made for the variety and quantity of final products and the corresponding physical volume as well as the other basic information; with the technical transformation or machinery and equipment updating, the corresponding basic information such as technical parameters will change, and so will the basic information of relevant factors. Under such circumstance, the modification of the basic information can be made manually. The corresponding optimal micro material-based input-output planning model can be established based on the market demand to direct enterprises' operation, however, the current AI is still on the level of ANI, with passwords only for the adjustment and modification of the variety and quantity of final products and the corresponding physical volume as well as of the corresponding basic information of machinery and equipment such as technical parameters and the basic information of relevant factors, the ability of AI needs to be equal to that of human's, which is AGI. 2) It is known that for building integration, information is the key to it and it is established by the departments of management, design, 
production (including the maintenance and transmission of information) and operation. The information exists in various ways and it can be processed automatically in different types of systems. For building integration, the information must be kept online instead of storing in a file box or on an offline disk. In other words, integration does not mean simply putting the information of each department on a computer and then making them communicate. The purpose of integration is to manage and direct the information in order to coordinate the operation of all functions. It can be imagined when the operation of the national economy is out of balance and even the damage control cannot be done, the level of AI must be on the same level of human's, which is AGI. By using integrated information to establish and realize the real-time analysis of the optimal micro material-based input-output planning model in order to guide the actual operation of enterprise' and realize the vision of coordinated operation. 3) The level of AI must reach the level of ASI in order to fulfill the tasks which are beyond human capability.

\subsection{Scientific Foundation of the Optimal Macro Input-Output Planning Model and AI}

The realization of combinations and connections between the optimal micro input-output planning model and the optimal macro input-output planning model is the key to realize the real-time analysis of the optimal macro input-output planning model. In the three major industries, the real-time analysis of the optimal macro value-based input-output planning model is chosen as an example to understand the general conception of system design and software development. In order to facilitate the description of the structure of this model, please refer to the basic table (Table 3-1) of China’s Value Table 1992 (Dong, 2000).

For establishing the optimal macro value-based input-output planning model and the optimal micro material-based input-output planning model by using ANI, the difference of the tabulation method is essential. However, according to the structure of input-output model as well as the economic significance, dependence and data source of each part, to simulate manual tabulation with ANI, the principle of steps and calculation methods of manual tabulation basically remains the same. Thus, only a brief introduction to the principle is made in this paper.

For example, 1) the database files designed according to the tabulation structure of the model are established based on the structure of the optimal macro value-based input-output planning model. The direction of input shall include intermediate input, added-value, total input of the major column, as well as name, specification, model, quantity, sum and other data of the specific objects to which they belong and the corresponding industry or department (product); the direction of output shall include use-in-process, use-at-the-end, other use, total output of the corresponding column, as well as name, specification, model, quantity, sum and other data of the specific objects to which they belong and the 
corresponding industry or department (product). Then, according to their quadrant and subordination from bottom to top in order to make them separately encoded and facilitate link and mergence; 2) according to industry or department (product) to which each specific object belongs and its corresponding name, specification, model, quantity, sum and other data, all the information can be respectively linked and merged from bottom to top based on the code. The result of the mergence can meet not only the requirements of basic data needed for the management of industry or department (product), but also the requirements of building the optimal macro value-based input-output planning model. By linking and merging the relevant basic data again one by one after receiving it, for the internal flow matrix, according to the allocation direction and consumption source of products and services which are planned by the department (product) in this period, the data of the specific objects can be linked and merged according to their corresponding name, specification, model, quantity, sum and so on. For other projects, according to name, specification, model, quantity, sum and other data corresponding to specific objects, it is convenient to link and merge the added-value in the major column as well as the use-at-the-end and other use in the corresponding column. Then the total output can be calculated according to the balance established in rows, and the total input can be calculated by the balance established in columns. The basic data of such is the basic data of the macro value-based input-output planning model; 3) the database files based on the fundamental data required for the mathematical model which is combined with the linear programming method by its basic data, the optimal structure scheme of product value can be laid out in order to realize the real-time analysis of the optimal macro value-based input-output planning model. It can be seen that according to the scientific thought, theory and method of real-time input-output tabulation method, as long as steps and calculation methods of manual tabulation are clarified, it is not difficult to use ANI technology to build the optimal macro value-based input-output planning model.

It must be pointed out that the optimal macro value-based input-output planning model is built on the basis of the optimal micro value-based input-output planning model, and the optimal micro value-based input-output planning model is built on the basis of the optimal micro material-based input-output planning model. The operation of national economy loses its balance because the imbalance occurs between material products, at this time, by adjusting the output of relevant micro models and re-establishing the optimal micro material-based and value-based input-output planning model, then re-establishing the optimal macro value-based input-output planning model in order to achieve instructive effect. Otherwise, by applying AGI or even ASI, the national economy can be adjusted in time.

The scientific basis of AI indicates that the process of machine learning is a process of continuous training, and the process of model optimization is a process of continuous adjustment which means models becoming more precise 
with more training data. Human learning is not only about continuous learning, but also a jump-type study which is often told insight learning. However, it has not happened for machine learning. It is important to point out that in the basic structure of the optimal macro input-output planning model, not only can each field and its objects be vertically included, but also the relationship between each field and its objects in horizontal line and in vertical line is objectively shown, that is interactional and interconnected. Because of interaction and interconnection of such between vertical line and horizontal line do not exist in any other public platform and common technology platform, on the basis of macro input-output model, technology file database which is established on its basic structure and the combination of technology and economy such as economy significance and substance can meet the requirements of public platform as well as common technology platform; technology database files of each industry can be established, so can the establishment of critical technology file database be accordingly brought along; trend of standard system shaping can be gradually evolved and basic needs of protocols such as data exchange and communication can be met as well.

\section{Combinations and Connections between the Internal Information of the Optimal Input-Output Planning Model and AI}

Combinations and connections between the internal information of the optimal input-output planning model and AI are mainly about how to solve tabulation problem. Because the basic data of the model itself has characteristics which the management attribute is natural and social, it can be regarded as an interface in which natural science and social science interact, interconnect and interpenetrate. In this interface, the data information of the model can be divided into internal information and external information. It must be pointed out that the concept of internal information is introduced to facilitate tabulation, and the concept of external information is introduced for model application. In this paper, no matter tabulation or model application, MPS accounting system and its corresponding model structure are used for budget (plan), policy analysis and accounting of national economy. In addition, no matter for joint ventures or foreign enterprises, in production, the tabulation of the optimal micro input-output planning model and micro input-output statistical model is not difficult. While the problem of merging the basic data of material volume and value volume one by one can be dealt with laws and regulations of nations and the scope of accounting contents. According to the scientific basis of AI, the database files built based on the fundamental data of the input-output model can be regarded as interfaces of combinations and connections between internal information and AI technology. After having those internal information interfaces, AI technology can be used to simulate artificial processing of the fundamental data of the input-output model and provide accurate and reliable basic data for 
creating the model. In addition, for the optimal material-based input-output planning model, those internal information interfaces ascertain economy significance and make actual work meet the needs as well as become foundation of the optimal material-based input-output model for worldwide use. Therefore, for realizing combinations and connections between internal information of the optimal input-output planning model and AI during the tabulation method, according to the characteristics and requirements of Industry 3.0 or Industry 4.0, the introduction of the tabulation method of the optimal micro material-based input-output planning model and micro material-based input-output statistical model is the important part of this paper. As long as tabulation method of those models is clear, the problems of other input-output tabulations will be easily solved. It is elaborated as following.

\subsection{Combinations and Connections between the Internal Information of the Optimal Micro Material-Based Input-Output Planning Model and AI}

Although scientific thought, theory and method of real-time input-output tabulation method have avoided a rigid way of putting input-output statistics table first and input-output planning table after according to the traditional tabulation of Leontief. As a main problem, the realization of the real-time analysis of the input-output planning table and timely analysis of input-output statistical table is thoroughly solved. However, in terms of the realization of the real-time analysis of the optimal micro material-based input-output planning model and the timely analysis of micro material-based input-output statistical model with the fundamental data, how to process the data is still the most difficult and complicated problem and it takes a heavy workload. In addition, in terms of the realization of the real-time analysis of the optimal micro material-based input-output planning model with the basic data, the technology database files that produce the fundamental data which is related to the basic data can be regarded as interfaces between the optimal micro material-based input-output planning model and AI technology. After obtaining these internal information interfaces, AI technology can be used to simulate the artificial processing of the fundamental data and obtain the basic data to realize the real-time analysis of the optimal micro material-based input-output planning model.

To this point, by taking the process of the product structure or BOM processing for the fundamental data interface which is based on the basic structure of the optimal micro input-output planning model as the example, basic methods of tabulation with AI technology are summarised as following.

\section{Method 1-The combination of manual tabulation and AI technology}

Combinations and connections between the optimal micro material-based input-output planning model and AI are realized through technology database files that are related to the fundamental data. Thus, while processing the fundamental data by using AI technology to simulate manual tabulation, it is necessary to accurately (referring to variety and quantity of products, the same as be- 
low) and precisely (referring to the physical volume of variety and quantity of products) generate the basic data with an appropriative algorithm (program) for realizing the real-time analysis of the optimal micro material-based input-output planning model. In terms of realizing the combination between manual tabulation and AI technology, the method can be described as following. For any new product, once it is shaped and put into production, according to the information provided by the design of final product, as long as the process of product structure or BOM is taken as the fundamental data which is based on the basic structure of the optimal micro material-based input-output planning model, technology database files of tabulation includes according to the classification of enterprise accounting, 1) variety and quantity of final products and the corresponding physical volume; 2) technical data of industry standard and database files of product standard technical parameter; 3) variety and quantity of semi-finished products and the corresponding physical volume; 4) the fundamental data of consumption quota and man-hour of semi-finished products in unit; 5) in each process of the consumption (input) of purchased products (such as components, raw materials, materials, auxiliary materials, power and so on), the technical data such as name, specification, model, volume and supplier of those purchased products; 6 ) the output of the previous process is the input of the current process and the output of the current process is the input of the succeeding one, and the external conditions as whether the shape and structure have changed. Therefore, the method of the combination between method of manual tabulation and AI technology is based on contents, technical data and external conditions of technology database files stated above. According to the method of relevant fundamental data processing, the appropriative algorithms (program) and principles of tabulation, for each product, with database files of the products, the variety and quantity of input and output and the corresponding physical volume of each process can be accurately calculated so as the ratio of input and output. With the ratio of each process, the basic data for the realization of the real-time analysis of the optimal micro material-based input-output planning model can be accurately calculated.

It is important to point out that the input-output model cannot solve the problem that is related to optimization, but by being combined with quantitative management technology (Operational Research), the optimal input-input-output planning model can always be built up. The optimal planning model that is used by enterprises will bring the best economic benefits. It is not only an important part of the scientific foundation of AI, but also the important content of technology database files which is related to the fundamental data processing.

\section{Method 2-The combination of Auto CAD and AI technology}

While using Auto CAD for the design of product structure (components) or BOM (formula), according to the basic information such as product structure, $\mathrm{BOM}$ and process requirements given from the drawings, the basic functions of relevant software can be increased according to basic requirements of realizing the real-time analysis of the optimal micro material-based input-output plan- 
ning model. For example, with the industry standard technology file and the relevant product standard technical parameter database file, it is possible to accurately calculate variety and quantity of products and the corresponding physical volume of both input and output in each process. After the volume of input and output of each process is known, according to the quota of consumption and man-hour, the consumption (input) of variety and the quantity of those purchased products and the corresponding physical volume in each process can also be accurately calculated. That is the basic data for the realization of the real-time analysis of the optimal micro material-based input-output planning model.

\section{Method 3-The combination of CAM and AI technology}

By using CAM computer system to test and verify products during manufacturing process in order to increase basic functions of the relevant software according to basic requirements of real-time analysis of the optimal micro material-based input-output planning model. For example, based on the data information provided at the time of test and inspection of products, adoption of industry standard technical information and relevant technical parameter database files of product standard, the variety and quantity of both input and output as well as the corresponding physical volume of each process can be accurately calculated. After the amount of input and output in each process becomes certain, according to the quota of consumption and man-hour, the consumption of variety and the quantity of those purchased products and the corresponding physical volume in each process can also be accurately calculated. That is the basic data for the realization of the real-time analysis of the optimal micro material-based input-output planning model.

\section{Method 4-The combination of 3D printing and AI technology}

By using 3D printing for conceptual designing and printing, in the process of product structure or BOM, the basic functions of relevant software can be increased according to basic requirements of realizing real-time analysis of the optimal micro material-based input-output planning model. For example, according to the correspondence between process of conceptual 3D designing and printing and the product structure or BOM processing, based on the data information provided from the design of physical products, with the database file of industry standard and the relevant product standard technical parameter database file, the data information of the whole process from raw material to final products can be calculated. Thus, the variety and quantity of input and output and the corresponding physical volume of semi-finished products of each process which corresponds to conceptual products can be accurately calculated, so as the technical data such as name, specification and model of input and output of those semi-finished products. After the volume of input and output of each process becomes certain, according to the quota of consumption and man-hour, the consumption of variety and the quantity of those purchased products and the corresponding physical volume of each process can also be accurately calculated. That is the basic data for the realization of real-time analysis 
of the optimal micro material-based input-output planning model. It must be noted that 3D printing can also make solid components based on method of layer-by-layer accumulation of material from AutoCAD data. The method is that the material is added by point-by-point accumulation to form a surface and surface-by-surface accumulation to form a body. This method provides a new opportunity for manufacturing development from the traditional structure which is "macro" to the integration of macro-micro structure.

\section{Method 5-The combination of future factories and AI technology}

Although 3D printing technology is brilliant in theory, however, it is difficult for it to replace mass production and become a primary production. Therefore, the study of the combination of future factory and AI has its great contemporary relevance. According to the official data provided by Siemens (German corporation), the so-called future factory is actually the digitalized one. The characteristics of the digitalized factory can be summarised as following; 1) the communication between products and production equipment; 2) all processes have been optimized and implemented by IT control; 3) during whole production, man controlled work is little, for example, at the beginning of production, printed circuit boards are installed on production line, all work is automatically controlled by machines thereafter; 4 ) all devices are connected to Internet which can exchange data in real time, important information can be observed through mobile terminals; 5) scanners installed in the whole factory record all processes in real time, the details such as welding temperature, patch data and test results; 6) distribution of raw materials is also automated and information based, when certain material is required, man controlled work is limited to, for example, scanning samples of materials and making bar code information transmitted to automated warehouses, then the instructions issued by ERP system will let automated logistics system finish the rest of work or sometime make changes for improvements. Therefore, the combination of future factories and AI technology is in fact, based on automation, information and intellectualization, in the process of product structure or BOM, basic functions of relevant software can be increased according to basic requirements of realizing the real-time analysis of the optimal micro material-based input-output planning model. Technology database files of relevant tabulations can be established with the methods mentioned above. By using the algorithm (program), the basic data for realizing the model can be accurately calculated.

Method 6-With the development of technology of control, computer, communication, network and other technologies, information exchange application rapidly covers from the area of all equipment to the area of supervision and management. In despite of the availability of the methods stated above, how to make those methods allow developing enterprises or even developing countries to benefit from the model management? To save time for tabulation as well as resources of labor, material and finance becomes the key to problems. For example, 1) for factories based on a large-scale assembly lines (non-automated op- 
eration), regardless of the production period or process complexity, according to rules and regulations (Kang, 2015) (same as below) which are matched with input-output model management, not only can the variety and quantity of the first product or the first batch of products of input and output and the corresponding physical volume along with the variety and quantity of the purchased products and the corresponding physical volume consumed (input) in each time of semi-finished product processing be accurately calculated in advance, but the variety and quantity and the corresponding physical volume of those purchased products in each process of semi-finished products can also be immediately obtained later. According to internal connection and distinction between the statistical model and the optimal planning model of micro material-based input-output (Kang, 2014a), it shows that, by combining the variety and quantity of input and output and the corresponding physical volume of each process in the previous step to the variety and quantity of purchased products and the corresponding physical volume consumed (input) in each process of semi-finished products, the micro material-based input-output statistical model of the first product or the first batch of products can be established. It can be seen that if the basic data of that statistical models can be used as the basic data for the optimal micro material-based input-output planning model of the second product or the second batch of products to direct enterprises' operation and so on, not only can the basic data of the optimal micro material-based input-output planning model be closer to actual data, but by doing half of the work, corresponding outcome can be doubled as well. 2) For the factories based on the manual operation (non-assembly lines), regardless of production period or the process complexity, according to rules and regulations which are matched with the input-output model management, any plan of production and operation that is prepared by using the idea of the optimal micro material-based input-output planning model, same results can be obtained when the corresponding column of the basic structure of the optimal micro material-based input-output planning model is seen as a special case in which $\mathrm{N}=1$. For example, once the variety and quantity of a small batch of products are determined, the variety and quantity the corresponding physical volume of semi-finished products of each process can be accurately calculated. Therefore, according to this basic data as well as the quota of consumption and man-hour, the consumption (input) of variety and quantity and the corresponding physical volume of the purchased products can also be accurately calculated. And this volume becomes the basic data of the basic structure of the optimal micro material-based input-output planning model in which the corresponding column is regarded as $N=1$. 3) For those processing enterprises, product drawings provide production information and it is the only basis for preparing a series of follow-up work such as production plan and financial plan, regardless of the production period or process complexity, according to rules and regulations which are matched with input-output model management. Any plan that is prepared by using the idea of the optimal micro ma- 
terial-based input-output planning model, same results can be also obtained when the corresponding column of the basic structure of the model is seen as the special case in which $\mathrm{N}=1$. For example, based on the basic information provided by the drawings, since the variety and quantity and the corresponding physical volume of semi-finished products per process can be accurately calculated. Therefore, according to this basic data as well as the quota of consumption and man-hour, the consumption (input) of the variety and quantity and the corresponding physical volume of those purchased products can also be accurately calculated. And this volume becomes the basic data of the basic structure of the model in which the corresponding column is regarded as $N=1$. 4) For enterprises that are able to meet requirements of $3 \mathrm{D}$ printing and customized production, comprehensively taking the above methods is suggested.

Special note: for industries of the primary industry, the production cycle is normally long and the changes in the process also take time to be made; for those of the secondary industry, the production cycle and the changes are differed from one another; for industries of the tertiary, the inherent differences exist between service industry and service organizations, but it can be seen that when budget (plan), policy analysis and accounting are applied, apart from application of the above methods, the corresponding column of basic structure of the optimal micro material-based input-output planning model can be regarded as a special case in which $\mathrm{N}=1$. The method is basically the same for those processing enterprises. By applying those methods, not only the requirements of classification accounting can be met, but with basic structure, theory, economic content and significance, internal relation and management requirement of input-output model, design and development of micro economic management information system can be regulated as well. At the same time of realizing the real-time analysis of finance management and supply-demand chain management, the standardized data can be provided according to the basic requirements of industries as well as the basic requirements of establishing the optimal macro input-output planning model for worldwide use.

It is important to point out that for all industries, no matter which type of tabulation method is used, because product variety, technology progress, management level and other factors are constantly changing, as long as the relevant fundamental data can be modified, the basic data of the optimal micro material-based input-output planning model can be changed accordingly.

\subsection{Combinations and Connections between the Internal Information of the Optimal Micro Value-Based Input-Output Planning Model and AI}

The basic data required for the optimal micro value-based input-output planning model is based on the basic data of the optimal micro material-based input-output planning model. The establishment of product cost is an initial investment which is transferred and accumulated during the process; and establishment of product value is initial investment and profit which are transferred 
and accumulated during the process. Therefore, not only can the price of products be calculated by using a direct or full consumption coefficient for parallel carry-over (the carry-over targets are the initial input and profit), but the composition of product price can be received as well. In here, the product price is factory price of self-made products. In this price system, no matter from semi-finished products or finished products, profit can be shown. Thus, according to classification of enterprise accounting, technology database files of the tabulation include, 1) based on the basic data of the optimal material-based input-output planning model, direct consumption coefficient and complete consumption coefficient in the matrix table of internal flow are calculated;2) based on the method of inventory management (first in-first out, last in-first out, moving weighted average and individual valuation, etc.), material volume in the flow matrix of the purchased products which are consumed by each production sector in the process of self-made products can be converted into value volume; 3) based on the data of fixed assets, low-value easily-consumed goods, salary of management personnel and workers, the depreciation and repair costs of fixed assets, expenses of low-value easily-consumed goods and salary of management personnel and workers can be calculated separately; 4) based on fixed assets, low-value easily-consumed goods and salary of managers which are allocated by management departments, fixed assets depreciation and repair cost, low-value easily-consumed goods cost and salary of management personnel can be calculated separately; 5) based on cost of depreciation and repair of common parts of fixed assets, expense prepaid, accrued expense, other expenses and profits; 6) based on price and quantity of relevant products and the balance between the vertical line and the horizontal line, material volume in the flow matrix of the internal enterprise can be converted into value volume; 7) based on value volume of semi-finished products of each production sector and the initial input and profit, the total input of value volume in each production sector can be calculated; 8) based on value volume of semi-finished products and final products in each production sector, the total output of value volume of each production sector can be calculated. This is the optimal value-based input-output planning model based on the basic data of the optimal material-based input-output planning model. With its value volume, the actual situation of enterprise environment and production activities at the time of schedule making is observed. Those technology database files can realize the real-time analysis of the optimal micro value-based input-output planning model, gradually unify classifications according to basic requirements of industries, and provide the basic data for the optimal macro value-based input-output planning model. In addition, in the above tabulation methods, when the column of the basic structure of the optimal micro material-based input-output planning model is regarded as a special case in which $\mathrm{N}=1$ for the small scale manufacturers and processing enterprises, according to the corresponding rules and regulations of the input-output model, it is shown that because 1) the total value of variety and quantity as well as the corresponding physical volume of related products of each production depart- 
ment are known; 2) the total value of variety and quantity as well as the corresponding physical volume of purchased products that need to be consumed (input) in process of semi-finished products of each production department are known; 3) the cost of fixed assets depreciation and repair, low-value easily-consumed goods, as well as the salary of management personnel and workers are known; 4) the expense of fixed assets depreciation and repair, low-value easily-consumed goods and management personnel allocated by management departments are known; 5) the cost of depreciation and repair, the expense to be paid and accrued, other expenses as well as profits to be shared by each production department are also known, according to the classification of enterprise accounting, the above basic data can be merged one by one based on the basic requirements of the industries, and provides the basic data needed for the optimal macro value-based input-output planning model.

It is important to note whether the allocation of common cost, such as expense to be prepaid, accrued expense, other expenses and common cost as supplementary production cost and manufacturing cost is scientific and satisfactory which will directly affect quality of the establishment of the value-based input-output planning model and the value-based input-output statistical model. In this regard, the matrix which is formed based on the cost of purchased products such as fuel, power and auxiliary materials, depreciation cost of fixed assets and labor compensation cost often becomes a rectangular matrix. Therefore, the first step is to convert the rectangular matrix into a square-shaped one with elementary transformation. Then the weight coefficient which is based on the eigenvalue of the square-shaped matrix makes the common cost shared, and the scientific basis of distribution method can be better ensured. In addition, the basic data of this rectangular matrix can be directly used to calculate the cost of each column respectively, then the cost of each column will be added together to obtain the total amount, and the total amount of each column will be calculated as a percentage of the total amount. By taking this percentage as the weight coefficient to make the common cost shared is also a feasible method. To sum up, the scientific thought, theory and method of real-time input-output tabulation method have been improved by overcoming disadvantages which are caused psychologically.

\subsection{Combinations and Connections between the Internal Information of the Micro Material-Based Input-Output Statistical Model and AI}

According to connections and distinctions of the basic data between the optimal micro material-based input-output planning model and the micro material-based input-output statistical model, apart from the basic data remains same in the first quadrant and the second quadrant, the basic data in the third quadrant is distinguished because the former is a planned value and the latter is an actual value.

With continuous development and innovation of computer technology, wire- 
less technology, field bus technology, industrial Ethernet technology, IT technology, sensor technology, robot technology and safety technology, after several important stages such as single machine automation, workshop automation, total automation of centralized control of whole plant (an integration of product design, quality monitoring, process control, supervisory control and factory management, etc.), the factory automation is now developed towards AI. Therefore, in terms of the basic data of the third quadrant of the statistical model, it does not matter that the factory automation is in which phase, AI technology can make the use of intellectualized means of labour, such as machinery and equipment in every link of supply-production-sale (supply and demand chain), so that the basic data can be provided according to product structure or BOM processing based on the realization of timely analysis of the statistical model. For example, for laying up, labor objects, such as raw materials, materials, fuels, drives and extra materials can be counted only after being E-labeled according to basic requirements of the tabulation which includes the basic information such as source, name, quantity, physical volume, price and so on; in terms of intellectualized means of labour, basic functions of software are added according to basic requirements of tabulation which should contain the basic information such as source, name, quantity, physical volume, price and expiration to be accounted. For delivery from storage, for the labor objects, name, application, quantity, price and other basic information need to be marked separately to become adopted; the same applied to intellectualized means of labour. For enterprises with zero inventory, even though the process of entering and leaving warehouse is simplified, but it is very important to attach the basic information of related products in the process of purchase and consumption, accounts keeping and payment making. The purpose is not only to take the basic information for relevant use, but also keep the very clear description for each piece of original item. Then the description can be checked according to actual needs of management and basic requirements of data utilisation can be met for Big Data, new Cloud Computing technology, Internet of Things or new internet industry and AI technology, and this is very important!

It must be noted that regardless of manufacturing or other industries of the primary industry, industries of the secondary or service industries and service organisations, according to the basic information recorded at the time of entering and leaving warehouse, for production or business management, the technology database files of tabulation for realizing the combination of internal information of the micro material-based input-output statistical model and AI can be summarised as following, 1) for the input (consumption) labor objects, electronic labels should be affixed to indicate the identity, characteristics and attribute in accordance with basic requirements of tabulation; 2) for intellectualized means of labour, basic functions of software can be added according to basic requirements of tabulation to show identity, characteristics and attribute. Obviously, those technology database files are basic work of the realization of AI. The so-called intellectualization, for labor objects, it is able to reflect name, 
source, specification, model, quantity, price and other basic information of labor objects; for means of labour, according to basic requirements of tabulation, it can be used to record how long each process takes, what resources are consumed, and the information such as number and price of processed products as well as the same information of means of labor. Evidently, this basic information creates interfaces between internal information and AI. The interfaces are not only the scientific basis of AI, but also the database which forms the basic data in the third quadrant of the micro material-based input-output statistical model; the above basic data can be gradually unified one by one and provides the basic data for the macro material-based input-output statistical model.

\subsection{Combinations and Connections between the Internal Information of the Micro Value-Based Input-Output Statistical Model and AI}

Because the basic data needed for the micro value-based input-output statistical model is based on the basic data of the corresponding micro material-based input-output statistical model. Moreover, format and name of the third quadrant in the micro value-based input-output statistical model are identical to those of the optimal micro value-based input-output planning model. The only difference is that while tabulating the micro value-based input-output statistical model, collection and distribution of the cost between finished products and products should be considered. In addition, in above tabulation methods, for enterprises of small scale manual production and processing enterprises, when the column of the basic structure of the micro material-based input-output statistical model is regarded as a special case in which $\mathrm{N}=1$, according to rules and regulations of the input-output model, it shows that, 1) as long as the total value of the variety and quantity of final products and the corresponding physical volume is certain; 2) so is the total value of the variety and quantity of purchased products and the corresponding physical volume as the cost (input) of semi-finished products; 3) fixed assets depreciation, repair expense, low value easily-consumed goods expense and salary of management personnel and worker of the production sector are certain; 4) fixed assets depreciation, repair expense, low value easily-consumed goods expense and salary of management personnel of the management sector; 5) cost of depreciation and repair, prepaid expense, accrued expense, other expenses and profits to be shared by each production sector are certain, according to classification of enterprise accounting, the above basic data can be gradually unified one by one according to basic requirements of industries and provides the basic data for the optimal macro value-based input-output planning model.

It must be pointed out that because of different reasons, in terms of low value easily-consumed goods of each production sector and management departments as well as the travel expense of management departments, between the budget (planned) and accounting, there are generally discrepancies. In order to present an actual situation, either the data of the original technology database files needs 
to be modified during the tabulation or new technology database files need to be created. In other words, apart from the expense of the low value easily-consumed goods and the travel expense need to be modified or technology database files need to be re-built, the technology database files used for the optimal micro value-based input-output planning model can be called directly while tabulating the micro value-based input-output statistical model. It can be seen that based on the basic data calculated from combinations and connections between internal information of the micro value-based input-output statistical model and AI technology, the timely analysis of the statistical model can be realized. It can gradually unify different categories according to basic requirements of industries and provide the basic data needed for the macro value-based input-output statistical model as well.

\subsection{Combinations and Connections between the Internal Information of the Optimal Macro Material-Based Input-Output Planning Model and AI}

It can be seen that from basic structure, economic significance and content of the optimal macro material-based input-output planning model, it is a product distribution flow table in the row of the first quadrant which is the quantity of products that are invested for themselves and other products as the cost (input). In the column, it is the composed production cost (input) table which is the quantity of each product as the consumption of itself and other listed products. In the row of the second quadrant, it is the table of final product distribution and use which reflects not only the distribution and use of all listed products in production cycle for the final consumption, accumulation and export, but the proportion of listed products for consumption, accumulation and export. In the column, it is the composed final product table which reflects that each final demand is composed by which listed products, and an actual physical form of national income is social net products.

The real-time analysis of the optimal macro material-based input-output planning model is based on the realization of the real-time analysis of the optimal micro material-based input-output planning model (including industries of the primary and the secondary industry as well as service industries and service organizations) as well as an equation (Dong, 2000) that is formed as a chessboard, in which semi-finished products + final products - import $=$ total products. Therefore, based on combinations and connections between internal information of the model and AI, for enterprises based on independent accounting, regardless of a single type or multiple types of products, according to the classification of enterprise accounting and basic requirements of industries, the basic data can be gradually unified with principles of bottom-up, top-down and the balance between the macro and the micro as well as classified according to the basic structure of the optimal macro material-based input-output planning model and specific requirements of tabulation (pure departments' requirements) to provide the accurate and reliable basic data. Thus, it can be seen that technol- 
ogy database files of combinations and connections between internal information of the model and AI includes, 1) a balance table of production and distribution of various products in the optimal micro material-based input-output planning model; 2) consumption of components, raw materials, auxiliary materials, power and other purchased products in each process of the production; 3) purchased products consumption in service industries and service organizations; 4) the data of import and export products and the corresponding physical volume in the international trade. Those are the basic data needed to realize the real-time analysis of the optimal macro material-based input-output planning model.

\subsection{Combinations and Connections between the Internal Information of the Optimal Macro Value-Based Input-Output Planning Model and AI}

The material-based input-output model can accurately reflect physical connections between main products; however, due to measurement units, it cannot be summed up in the column; the forming process of product value therefore cannot be reflected. Because the value-based input-output model takes currency as its measurement unit, its basic function has been further expanded comparing with the material-based input-output model. Therefore, the economic significance of the basic structure of the value-based input-output model is similar to that of the material-based input-output model in spite of some differentiations there. The real-time analysis of the optimal macro value-based input-output planning model is based on the realization of the optimal micro value-based input-output planning model (including industries of the primary and the secondary industry as well as service industries and organisations) and the equations (Dong, 2000) formed as the chessboard, in which net export = export import, intermediate consumption + final consumption + other $=$ total output, intermediate input + added-value $=$ total input. Therefore, according to combinations and connections between internal information of the model and AI, as well as the classification of enterprise accounting and basic requirements of industries, the basic data can be gradually unified with principles of bottom-up, top-down and the balance between the macro and the micro, it can also be classified according to the basic structure of the optimal macro value-based input-output planning model and specific requirements of the tabulation (pure departments' requirements) to provide the accurate and reliable basic data. Thus, it can be seen that technology database files of combinations and connections between internal information of the model and AI include, 1) the balance table of production and distribution of various products in the optimal micro value-based input-output planning model; 2) the value of purchased products in the third quadrant; 3 ) depreciation and repair cost of fixed assets of production and management departments, low value easily-consumed goods cost of production and management departments as well as salary of management personnel and workers of production and management departments; 4) depreciation and repair cost of fixed assets to be shared by each production department, pre- 
paid expense, accrued expense, tax, other expenses and profits. In addition, those files also include cost of depreciation and repair of fixed assets, low-value easily-consumed goods as well as salary of management personnel of macro management; the cost of depreciation and repair of fixed assets that should be apportioned among overall common parts; overall prepaid expense, accrued expense and other overall expenses as well as the data of import and export products and the corresponding value volume in the international trade, etc. Those expenses and profits are the basic data needed to realize the real-time analysis of the optimal macro value-based input-output planning model.

\subsection{Combinations and Connections between the Internal Information of the Macro Material-Based Input-Output Statistical Model and AI}

The realization of the timely analysis of the macro material-based input-output statistical model is based on the timely analysis of the micro material-based input-output statistical models (including industries of the primary and the secondary industry as well as service industries and service organisations) as well as the equation (Dong, 2000), semi-finished products + final products - import $=$ total products. Therefore, according to the basic method of combinations and connections between internal information of the micro material-based input-output statistical model and AI, for enterprises based on independent accounting, regardless of a single type or multiple types of products, according to the classification of enterprise accounting and basic requirements of industries, the basic data can be gradually unified with principles of bottom-up, top-down as well as the balance between the macro and the micro, it can also be classified according to the basic structure of the macro material-based input-output statistical model and specific requirements of the tabulation (pure departments' requirements) to provide the accurate and reliable basic data. Thus, it can be seen combinations and connections between the internal information of the macro material-based input-output statistical model and AI is similar to which between the internal information of the optimal macro material-based input-output planning model and AI. The technology database files include, 1) balance tables of production and distribution of various products of the micro material-based input-output statistical model; 2) the consumption of components, raw materials, auxiliary materials, power and other purchased products of each process; 3 ) purchased products consumption of service industries and service organisations as well as the data of import and export products and the corresponding material volume in the international trade. Those are the basic data needed to realize the timely analysis of the macro material-based input-output statistical model.

\subsection{Combinations and Connections between the Internal Information of the Macro Value-Based Input-Output Statistical Model and AI}

Because the timely analysis of the macro value-based input-output statistical 
model is realized on the basis of the realization of the timely analysis of the micro value-based input-output statistical model (including industries of the primary and the secondary industry as well as service industries and organisations) and the equations (Dong, 2000), net export $=$ export + import, total output $=$ intermediate consumption + final consumption + other, total input $=$ intermediate input + added-value. Therefore, according to the basic method of combinations and connections between internal information of the macro value-based input-output statistical model and AI as well as the classification of enterprise accounting, the basic data can be gradually unified with principles of bottom-up, top-down as well as the balance between the macro and the micro, it can also be classified according to the basic structure of the macro value-based input-output statistical model and specific requirements of the tabulation (pure departments' requirements) to provide the accurate and reliable basic data. Thus, it can be seen that combinations and connections between the internal information of the macro value-based input-output statistical model and AI is similar to which between the internal information of the optimal macro value-based input-output planning model and AI. The technology database files include, 1) balance tables of production and distribution of various products in the micro value-based input-output statistical model; 2) value of purchased products in the third quadrant; 3 ) depreciation and repair cost of fixed assets of production and management departments; 4) low value easily-consumed goods cost of production and management departments; 5) salary of the management personnel and workers of production and management departments; 6) the cost of depreciation and repair of fixed assets to be shared by each production department; 7) prepaid expense, accrued expense, tax, other expenses and profits. In addition, those also include the expense of depreciation and repair of fixed assets, cost of low-value easily-consumed goods and salary of management personnel of the macro management; the cost of depreciation and repair of fixed assets that should be apportioned among overall common parts; overall prepaid expense, accrued expense and other expenses as well as the data of import and export products and the corresponding material volume in the international trade. Those expenses and profits are the basic data needed to realize the timely analysis of the macro value-based input-output statistical model.

Combinations and connections between the internal information of the optimal input-output planning model and AI show that by realizing the combinations and connections between $\mathrm{AI}$ and the internal information of both the optimal micro material-based input-output planning model and the micro material-based input-output statistical model are the basis of the combinations and connections between AI and the internal information of other optimal input-output planning models and $\mathrm{AI}$ and other input-output statistical models. In addition, for the tabulation, on the one hand, based on the realization of automation, information and intellectualization of means of labour, as long as basic functions of corresponding software are added according to basic requirements 
of the realization of the real-time analysis of the optimal micro material-based input-output planning model and the timely analysis of the micro material-based input-output statistical model, the purpose of the tabulation can be achieved. On the other hand, for those enterprises that intend to realize automation, information and intellectualization, the feasible plans of the tabulation are also put forward to meet their requirements of development. In particular, to combine Auto $\mathrm{CAD}$, drawing and manufacturing software and 3D printers altogether with AI, a principle which is similar to simulation technology can be taken as a basic method of data collecting and processing, and this is the key technology to the tabulation of the optimal micro material-based input-output planning model. It must be pointed out that according to the above tabulation methods of the optimal micro material-based input-output planning model, for those standardized product units, in order to calculate the quantity of corresponding material regarding product structure (components, same as below) and BOM (food, medicine and chemical industry, referred as "formula", same as below), based on the database files of the product standard technical parameter, the engineering designers (product structure designers and process route designers, same as below) can directly receive or accurately compute the number; for the calculation of the non-standardized product units, the engineering designers carry on their work according to the basic requirements of products, such as function and application, as well as the material type according to the product structure or BOM, based on the database files of the product standard technical parameter, the number can also be directly received or accurately computed because the basic information of the material is known in terms of its name, model, number and specification; with regard to the product units for special use, the number desired can be accurately calculated by firstly scanning the corresponding material regarding to the product structure or BOM to directly measure the dimension, then with the calculation based on the relevant specific weight, or by simply measuring directly with an electronic scale, thus, the basic data required for the tabulation can be conveniently obtained. Therefore, for manufacturing, the skilful technicians in engineering who carry on their work in design of the product structure or BOM have the access to the fundamental data that can not only meet the requirement of providing the basic data for establishing the micro material-based input-output planning model, but provide the basic information of the basic data needed based on the requirement. Thus, for those skilful technicians engaged in the plan of production and operation, they can make the plans according to the fundamental information of product drawings and the micro material-based input-output planning model according to database files of the product standard technical parameter in order to direct the following actual operation. It is not difficult to see that for the skilful technicians of engineering design as well as production and operation planning, the basic knowledge of organic combinations and connections between the macro and the micro is what they need, then the establishment of the micro ma- 
terial-based input-output planning model will be easy to achieve. As the smallest scientific discovery, because the basic data needed for the realization of the real-time analysis of the micro material-based input-output model can be calculated in advance, it becomes the theoretical basis of the real-time input-output tabulation method which is unique and novel as well as the foundation of the scientific thought, theory and method of the real-time input-output tabulation method. Moreover, For other sectors such as the highly modernized mining industry, construction and infrastructures, hydropower, oil and gas production, as well as highly modernized agriculture and service industries, the process of production or operation is not as continuous as the manufacturing of product structure (components) or BOM (formula), the variety and quantity of the input of each process and the corresponding physical volume can be accurately calculated in advance, however, for highly modernized agriculture and services industries in certain developed countries, the United States, for instance, there are still many similarities between the two processes. For example, depending on the function of each machine and equipment as well as the processing time of production or operation, the variety and quantity of the products and the corresponding physical volume can be calculated by the engineers engaged in those sectors within the fixed time; for the engineers engaged in agriculture (including agriculture, forestry, animal husbandry, fisheries) or service industries [including only the final services to customers and the intermediate services to producers (including the producers of service industries)], according to the respective area to which industry it belongs and the specific objects included in each area, depending on the function of each machine and equipment as well as the processing time production or operating, the variety and quantity of the products and the corresponding physical volume can also be calculated within the fixed time. It must be noted that for highly modernized agriculture or service industries, the variety and quantity of the certain products and the corresponding physical volume obtained after are accounting value, thus it is more accurate than the variety and quantity of the certain products and the corresponding physical volume estimated beforehand which are calculation value.

\section{Combinations and Connections between the External Information of the Optimal Input-Output Planning Model and AI}

The application of models is the solution of realizing combinations and connections between external information of the optimal input-output planning model and AI. According to the scientific basis of AI, the external information of the optimal input-output planning model is based on the real-time analysis of the optimal input-output planning model, and on the basis of the basic data of the model, technology database files become interfaces of the combinations and connections between the external information of the model and AI. It must be pointed out that MPS and SNA have their respective advantages, calibers of MPS 
can be adjusted to match those of SAN through conversion. It can be seen that after conversion, database files which are drawn up separately on the basis of the basic data of the model corresponding to SNA accounting system are also interfaces. For the model application, no matter which accounting system (MPS or SNA) will be adopted, after having those interfaces of the external information, on the one hand, the models can be called directly for traditional or commonly use of research, analysis, forecasting (planning) of economy, policy research, economic accounting, etc. to obtain results which are basically consistent with actual situations; on the other hand, Big Data, new Cloud Computing technology can be used to excavate the massive data produced by means of labor, such as intellectualized machinery and equipment of cross-boundary economic management information system or Internet of Things or internet in order to track, supervise and analyse the actual operation of national economy. The summary is given as following.

\subsection{Combinations and Connections between the External Information of the Optimal Micro Material-Based Input-Output Planning Model and AI}

For the optimal micro material-based input-output planning model (including industries of the primary and the secondary industry as well as service industries and organisations of the tertiary industry), because the basic structure of the model can objectively reflect the whole process of enterprises engaged in production and business activities in accordance with technology processes, it can also reflect balance of supply, production and sale of various products as well as the quantity and flow direction of various products among various production sectors; the basic data of the optimal micro material-based input-output planning model is a guide for future work such as plans of production, purchase, finance, progress and so on. Therefore, no matter on what stage the automation is, combinations and connections between the external information of the optimal micro material-based input-output planning model and AI are aimed at the basic data of the model. On the basis of realizing the intellectualization of means of labor, each process of product structure or BOM can produce not only a large amount of real-time data of the variety and quantity of input and output and the corresponding physical volume, but a large amount of real-time data of the variety and quantity of purchased products and the corresponding physical volume which need to be consumed (input). This shows that by using Big data, new Cloud Computing technology, Internet of Things or new internet industry and $\mathrm{AI}$, on the one hand, based on basic requirements of the optimal micro material-based input-output planning model, this vast amount of data can be automatically excavated in order to track, monitor, and analyse real-time situation from internal management such as purchase, inventory, plan-production-sale to logistics, collaborative processing and delivery service, as well as each link of the external management such as commercial circulation which makes production and business activities generate a tight link from supply to demand and the flow 
of resources that is related to supply and demand chain to ensure consumption of material, human resources, finance, equipment and so on in the best state; on the other hand, it can precisely lock resources needed in production to ensure that all aspects of enterprises engaged in production and business activities can proceed smoothly in accordance with the law of coordination developments as well.

\subsection{Combinations and Connections between the External Information of the Optimal Micro Value-Based Input-Output Planning Model and AI}

The optimal micro value-based input-output planning model (including industries of the primary and the secondary industry as well as service industries and organisations of the tertiary industry) is established on the basis of the real-time analysis of the optimal micro material-based input-output planning model. Therefore, combinations and connections between the external information of the optimal micro value-based input-output planning model and AI aim at the basic data of the model and through the volume of value to track, supervise and analyse enterprises which are engaged in production and business activities. For example, by using Big data, new Cloud Computing technology, Internet of Things or new industry of internet and AI, on the one hand, the basic data of the optimal micro material-based input-output planning model can be converted into the corresponding value volume and to track, monitor and analyse and ensure tight connections between the optimal micro material-based input-output planning model and the optimal micro value-based input-output planning model. On the other hand, a whole procedure starts with suppliers and warehouse and by following the links of process (raw materials - semi-finished products finished products - products for sale) then completes with customers. According to basic requirements of the optimal micro value-based input-output planning model, through the data information that is generated from means of labor of each process and link to track, supervise and analyse whether production and business activities are in accordance with the law of coordination development. This is the key technology for avoiding waste of resources and fraud. At the same time, the cost of depreciation and repair of fixed assets and low-value easily-consumed goods, salary, prepaid expense, accrued expense, other expense and profit, etc. can be better tracked, supervised and analysed according to the classification of enterprise accounting, and it is a scientific method to improve enterprise management, control cost and raise economic efficiency.

\subsection{Combinations and Connections between the External Information of the Micro Material-Based Input-Output Statistical Model and AI}

The micro material-based input-output statistical model (including the industries of the primary and the secondary industry as well as service industries and service organisations of the tertiary industry) is established on the basis of rea- 
lizing the real-time analysis of the optimal micro material-based input-output planning model. The only difference between the two is that in the third quadrant, the basic data of purchased products is different. The basic data of the former is an actual value, and that of the latter is a planned value. It can be seen that no matter on what stage the automation is, combinations and connections between the external information of the micro material-based input-output statistical model and AI are based on the basic data of the third quadrant of the optimal micro material-based input-output planning model. By comparing and analysing the basic data of the third quadrant from the both models one by one, the method for solving the problems which exist in production and management can be found. Since the purpose of establishing the micro material-based input-output statistical model is no longer about providing data in the traditional way to support the establishment of the optimal micro material-based input-output planning model, it becomes a method of comprehensive accounting (stock-taking, same as below) and audit. For example, based on the basic data of the optimal micro material-based input-output planning model to check whether the balance is there between the data and the actual situation such as consumption, inventory, accounting and purchase, and this is the scientific method to control the quantity. In addition, from the process of generating the basic data needed for the third quadrant and sources of the data information, it is shown that by using Big data, new Cloud Computing technology, Internet of Things or new industry of internet and AI, on the one hand, the consumption (input) of the variety and quantity of purchased products and the corresponding physical volume can be comprehensively calculated and audited. On the other hand, the internal management can be expanded from purchase, inventory, plan-production-sale to logistics supply, collaborative processing, delivery service as well as commercial circulation and other external management. In this case, production and business activities are formed as a tight link from supply to demand, and comprehensive accounting and audit can be conducted for this supply and demand chain. This scientific method is for improving accounting and audit.

\subsection{Combinations and Connections between the External Information of the Micro Value-Based Input-Output Statistical Model and AI}

The micro value-based input-output statistical model (including the industries of the primary and the secondary industry and service industries and organisations of the tertiary industry) is established on the basis of realizing the timely analysis of the micro material-based input-output statistical model. Therefore, combinations and connections between the external information of the model and AI are based on the basic data of the model itself, and by applying the volume of value to conduct comprehensive accounting and audit for production and business. The purpose of establishing micro value-based input-output statistical model is not about providing data for accounting anymore, it is about a 
comprehensive accounting and audit as well. Therefore, the content of accounting and audit of the micro value-based input-output statistical model and that of the micro material-based input-output statistical model is basically the same. The method of using Big Data, new Cloud Computing technology, Internet of Things or new internet industry is not again given.

\subsection{Combinations and Connections between the External Information of the Optimal Macro Material-Based Input-Output Planning Model and AI}

The optimal macro material-based input-output planning model is established after realizing the real-time analysis of the optimal micro material-based input-output planning model (including industries of the primary and the secondary industry and service industries and service organisations of the tertiary industry). Combinations and connections between the external information of the model and AI is based on the basic data of the model itself to track, supervise and analyse all aspects involved in the macro-economic operation through the volume of material. For example, by taking advantage of Big data, new Cloud Computing technology, Internet of Things or new industry of internet and AI, on the one hand, according to the basic structure, economic significance and content of the model and principles such as bottom-up, top-down and the balance between the micro and the macro, as results, all types of the optimal micro material-based input-output planning models must be merged one by one according to a transitive relation between them and sectors (products) of the optimal macro material-based input-output planning model. On the basis of applying the basic data of the optimal micro material-based input-output planning model to track, supervise and analyse micro-economic operation, the basic data of the optimal macro material-based input-output planning model can be also applied in order to track, supervise and analyse whether the macro-economic operation is in accordance with the objective law of coordinated development or measurements need to be taken. On the other hand, according to rules and regulations associated with the input-output model management, the classification of enterprise accounting and basic requirements of macro-economic management as well as the actual situation of macro-economic operation, the implementation of rules and regulations on different levels can also be tracked, supervised and analysed to ensure the smooth operation of macro-national economy.

\subsection{Combinations and Connections between the External Information of the Optimal Macro Value-Based Input-Output Planning Model and AI}

The optimal macro value-based input-output planning model is established on the basis of realizing the real-time of the optimal micro value-based input-output planning model (including industries of the primary and the secondary industry and service industries and organisations of the tertiary industry). Therefore, combinations and connections between the external information 
of the model and AI is based on the basic data of the model itself to track, supervise and analyse all aspects involved in the macro-economic operation through the volume of value. The basic data of the optimal macro value-based input-output planning model includes not only the basic data of the optimal micro value-based input-output planning model, but also the expenses of macro management departments and macro management organisations. It can be seen that by applying Big data, new Cloud Computing technology, Internet of Things or new industry of internet and AI, on the one hand, according to the basic structure of the optimal macro value-based input-output planning model and principles such as bottom-up, top-down and the balance between the micro and the macro, as results, all types of the optimal micro value-based input-output planning models must be merged one by one according to the transitive relation between them and sectors (products) of the optimal macro value-based input-output planning model. Based on applying the basic data of the optimal micro value-based input-output planning model to track, supervise and analyse micro-economic operation, the basic data of the optimal macro value-based input-output planning model can be applied as well to track, supervise and analyse whether the macro-economic operation is in accordance with the objective law of coordinated development or measurements need to be taken. On the other hand, according to rules and regulations which are associated with the input-output model management, the classification of enterprise accounting and basic requirements of macro-economic management as well as the actual situation of macro-economic operation, the implementation of rules and regulations on different levels can also be tracked, supervised and analysed to ensure the smooth operation of macro-national economy.

\subsection{Combinations and Connections between the External Information of the Macro Material-Based Input-Output Statistical Model and AI}

The macro material-based input-output statistical model is established on the basis of realizing the timely analysis of the micro material-based input-output statistical model (including industries of the primary and the secondary industry and service industries organisations of the tertiary industry). Therefore, combinations and connections between the external information of the model and AI are based on the basic data of the model, and by applying the volume of material to conduct comprehensive accounting and audit for the macro-economic operation. For example, by using Big Data, new Cloud Computing technology, Internet of Things or new industry of internet and AI, on the one hand, according to the basic structure of the macro material-based input-output statistical model and principles such as bottom-up, top-down and the balance between the micro and the macro, as results, all types of the micro material-based input-output statistical models must be merged one by one according to the transitive relation between them and sectors (products) of the macro material-based input-output statistical model. On the basis of applying the basic data of the micro materi- 
al-based input-output statistical model for accounting and audit, the macro-economic operation can be respectively and comprehensively calculated and audited according to the basic data of the macro material-based input-output statistical model. On the other hand, according to rules and regulations associated with the input-output model management, the classification of enterprise accounting and basic requirements of macro-economic management as well as the actual situation of national economic operation, by comparing the basic data of the macro material-based input-output statistical model and that of the optimal macro material-based input-output planning model one by one, problems of the implementation can be revealed on each management level, and solutions will be found accordingly.

\subsection{Combinations and Connections between the External Information of the Macro Value-Based Input-Output Statistical Model and AI}

The macro value-based input-output statistical model is established on the basis of realizing the timely analysis of the micro value-based input-output statistical model (including industries of the primary and the secondary industry as well as service industries and organisations of the tertiary industry). Therefore, combinations and connections between the external information of the model and AI are based on the basic data of the model and by applying the value volume to conduct comprehensive accounting and audit for the macro-economic operation. For example, by using Big Data, new Cloud Computing technology, Internet of Things or new industry of internet and AI, on the one hand, according to the basic structure of the macro value-based input-output statistical model and principles such as bottom-up, top-down and the balance between the micro and the macro, as results, all types of the micro value-based input-output statistical models must be merged one by one according to the transitive relation between them and sectors (products) of the macro value-based input-output statistical model. On the basis of applying the basic data of the micro value-based input-output statistical model for accounting and audit, the macro-economic operation can be respectively and comprehensively calculated and audited according to the basic data of the macro value-based input-output statistical model or measurements will be taken. On the other hand, according to rules and regulations associated with the input-output model management, the classification of enterprise accounting and basic requirements of macro-economic management as well as the actual situation of national economic operation, by comparing the basic data of the macro value-based input-output statistical model and that of the optimal macro value-based input-output planning model one by one, implementation problems can be revealed on each management level, and solutions will be found accordingly.

Combinations and connections between the external information of the optimal input-output planning model and AI show that the external information changes with changes of the internal information, and the external information 
is determined after the confirmation of the internal information. Therefore, for management personnel, they can modify neither the internal information, nor the external information. For model application, since the accuracy of the basic data in the optimal input-output planning model or that of the cross-boundary economic management information system is fully guaranteed, therefore, waste of resources and fraud can be thoroughly avoided.

\section{System Reviews}

At present, another round of industrial revolution with intellectualized manufacturing as the main content is set off around the world. A deep integration of the new generation of information technology and manufacturing industry brings profound industrial changes and forms a new mode of production, new form of industry and business as well as a new economy growth point. Among them, enhancing the ability of IT management will become a focus of enterprises. At this moment, humans have accomplished mastering the scientific method of applying ANI. In fact, ANI is getting involved in our daily life. AI revolution starts from ANI through AGI and eventually reaches ASI. Humans might not see that happen but the world will be after all completely different. Thus, it can be seen that the scientific basis of input-output real-time tabulation method and AI needs to adapt to development and change of the coming social industry structure as well as development and change of future social economy management. Nothing is easy at the beginning but with great efforts, achievements will be able to make. In 1991, a trial run was conducted in Cotton Textile Factory of Guiyang and as the first substantive result, the software system with ANI application was merely a preliminary attempt of tabulation by using AI technology and it was even far from the overall goals. However, once the first step was taken and a good start was made, then we would be at least halfway to the success. Thus, the next thing to do will become much easier. In this regard, it is not difficult to draw following conclusions.

1) The idea of solving the problem of tabulating and model application with AI (computers) may seem impossible; however, it is actually the most promising solution. This is because by making computers study of AI and modifying their own code, not only can their own structure be improved, but the computers can directly be turned into computer scientists. How to improve the intelligence of computers thus becomes the task of the computers themselves. In terms of calculating speed of a human brain, it reaches maximum 200 hertz while a present micro-processor can operate at $2 \mathrm{G}$ hertz which is 10 million times faster. The information processing speed of a human brain is 120 meters per second while the speed of computers is the speed of light. The difference is rather large which is several orders of magnitude. In terms of capacity, the human brain capacity cannot be made any bigger; even it could, its limited speed would have become a huge drawback. The physical size of computers can be very adjustable, with more hardware, larger memory, long-term effective storage medium, they can be 
much more capable and accurate than the human brain. In terms of reliability and durability, the human brain easily tends to fatigue while computers can operate at peak speed 24 hours a day. The storage capacity of computers is stronger because their transistors are more accurate, and those transistors can be repaired or even replaced. In terms of software, it is editable and upgradable with much more possibilities to be improved more effective. Computers can be as good as the human brain in terms of visual elements as well as engineering elements that can be strengthened and optimized. In terms of collective capability, from languages in the early stage and the formation of large communities to the invention of written language, printing and internet, human being becomes unchallengeable; however, computers can do much better. An AI network that runs specific programs can easily synchronize itself around the world, what one of those computers has learnt will be immediately available for all other computers, and computer clusters can perform a same task together because characteristics such as divergence, motivation, self-interest in humans do not appear in computers. By creating AGI computers that are comparable to human intelligence, a harmonious human society might not be far away because the computers will be used to comprehensively manage and regulate the foundation of social economy according to human's pre-set. This shows that human level intelligence will be an important milestone while AI will be able to create itself AGI through self-improvement but fortunately, it will not stop moving forward from there. Considering that AGI needs to be greater than human brain, it will quickly pass through the human level and head towards ASI.

2) In the three major industries, technology database files which are built based on the technology files of the industry standard and the technical parameter of product standard are used as the starting point for the future development. Once the research, analysis, accounting and forecasting (planning) of economy, policy research and other functions can be classified and numbered in advance as well as the database files can be organised, then all requirements will be met through a man-made command. In addition, the effect of respectively applying Big data, new Cloud Computing technology, Internet of Things or new industry of internet and $\mathrm{AI}$ is, in the environment of combinations and connections between the internal information and the external information of the optimal input-output planning model and AI, regardless of micro-economic operation or macro-economic operation, while the operation of national economy is in an imbalanced situation which is caused by either natural or man-made disasters and the imbalance is beyond the scope of remediation, by using Big data and new Cloud Computing technology to excavate a vast amount of data that is generated by means of labor, such as intellectualized machinery and equipment of cross-boundary economic management information system or Internet of Things or internet as well as on the basis of realization of tracking, supervising and analysing the operation of national economy, AI can help estimate with the law of coordinated development whether it exceeds damage control, then automatically 
simulates real-time artificial analysis and process based on the integrated data and carry out corresponding procedures to achieve the expected goal.

3) According to the basic data of the optimal macro material-based input-output planning model, by using the data of the material volume of relevant products of cross-boundary economic management information system or Internet of Things or internet, the balance of supply and demand can be tracked, monitored and analysed. In case of the existence of discrepancies, the basic data information such as cause, location and cost of those discrepancies will provide decision makers based on the theoretical basis. In other words, by creating alternatives through certain technology or method that can imitate human thinking and behaving to help human accomplish the work in certain fields. In addition, the industries and the objects to which those industries belong, when they are involved in the realization of the real-time analysis of the optimal macro material-based input-output planning model, a massive amount of data is generated by means of labor, such as intellectualized machinery and equipment based on various products and the circulation of logistics, information flow and capital flow. According to classification and code of those means of labor, it will be clear that the products and the circulation of corresponding logistics, information and capital flow are from what object and which industry as well as the massive amount of data. In this regard, with Big data, new Cloud Computing technology, Internet of Things or new internet industry and AI, based on monthly production cycle, the massive amount of data of those products and the logistics, information and capital flow will be analysed for tracking, monitoring and analysing the actual operation of national economy as well as for supervising the enforcement of rules and regulations according to the objective law of coordinated development. This is the only way for the optimal input-output planning model to play a leading role in construction and development of national economy.

4) As methods, based on Internet of Things or new internet industry and AI and according to the traditional operation process, Big Data and new Cloud Computing technology can be used for the following tasks, through correlation analysis, customers, users and products can be connected together and user preference and customer relationship can be individualized into user-driven products and customer-oriented services. In such process, each type of resource digging mode, actual situation and reserves distribution can be searched and analysed then formed as a visual map of resource distribution for enterprises. It is like using electronic map to digitalise and visualise all kinds of virtual advantages point to point, with thorough management, managers can put existing and potential resources in use more effectively; by using the data provided by Big data and new Cloud Computing technology to plan production structure and process, it can not only help enterprises explore an unknown value combination of traditional data, but provide one-to-one solutions to detailed problems as well as a guarantee to production; with the analysis made by Big data and new Cloud 
Computing technology, according to different brands intersecting and overlapping in the data of market, the operation direction of the business will be intuitively and easily identified; brand promotion, location choice, strategy planning and other works can be better handled; by applying Big Data and new Cloud Computing technology to dig the data from social contacts and customer interaction, it can help enterprises to carry out the work which is related to balance design and fragmentation expansion for brand information. Richard H. Thaler, the economist argued that "even the slight change of an individual's view can have major impacts on group behaviour patterns". In the background of those major impacts, enterprises must pay attention to every small flow of information in order to meet requirements of customers, every detail is a key to success.

5) According to requirements of future factory automation, the high modernization and integration of product design, manufacturing, processing and sale should be realized. In terms of the technology support of future factory automation, it cannot be separated from management engineering, system engineering, information technology, automation technology, market economics, etc.; based on the application of Big data, new Cloud Computing technology, Internet of Things or new internet industry and AI technology, resource sharing can be implemented, and efficiency and effectiveness of production can be improved. It can be seen that for giving full play to the comprehensive roles in construction and development of national economy, to combine them with the optimal input-output planning model is the only way. Therefore, in the process of combining, the basic data of tabulation should be regarded as one of key contents of research and development from now. The realization of combinations and connections between these methods and the optimal input-output planning model is the best approach, in terms of progress and improvement of human society and its technology, as well as productivity, the maximum efficiency can be made with half of the work as well. The future factories will become smart factories, a high efficiency will be made accordingly, substandard products, downtime, waste and laying-off and falsification, for example, will be eliminated. By effectively working together, managers and employees ensure that data and production, IT and manufacturing are seamlessly integrated to make each rotation of every machine, each cutting of every tool and each delivery of every component in the global delivery chain precise and observable.

6) The basic functions of real-time input-output tabulation method, for International Input-Output Association, the problems of "out-dated data and presumed data" existing in the analysis of the optimal material-based and value-based input-output planning model which are related to production model have been thoroughly solved. However, the optimal macro input-output planning model applied on regional and national level also includes agriculture, forestry, animal husbandry, fish industry in the primary industry, other sectors of the secondary industry, as well as the service organizations in the third industry, it is thus difficult to predict (plan) accurately. It must be pointed out that 
whether it is $3 \mathrm{D}$ printing of the current Industry 3.0 or customized production of the future Industry 4.0, after the implementation of the real-time input-output tabulation model method and cross-boundary economic management information system, the basic data needed in the optimal macro input-output planning model on regional and national level will be automatically merged, generated and collected from the basic data of the optimal micro input-output planning model, but the basic data of the optimal material-based and value-based input-output planning model which is related to production model is more accurate and reliable than the basic data in the optimal macro input-output planning model on regional or national level; the basic data of the macro input-output statistical model on regional and national level is more accurate and reliable than the basic data of the optimal macro input-output planning model on regional or national level. For International Accounting Association, enterprises that realize the real-time analysis of the optimal micro input-output planning model and the micro input-output statistical model can completely solve the problem of how to model the financial management system and supply-demand chain management system. This is because on the basis of the common basic data (product structure or BOM, process routes, consumption quotas and man-hour quotas, capacity resources and inventory data, etc.) and in a unified data environment (a unified data environment such as the basic data of optimal micro input-output planning model and micro input-output statistical model, etc.), not only can combinations and connections between those two models be established, but the basic structure of the optimal micro input-output planning model can be used to plan accounting subjects and establish accounting systems as well. Also, by making the real-time analysis of the optimal micro input-output planning model and the timely analysis of the micro input-output statistical model the basis and core to establish accounting theory, principles, standards and methods as well as management methods (Kang, 2014b). For International Management Association, the problem is basically solved in terms of how management can stretch across two different fields which are natural science and social science at the same time, and the interface in between is interlinked, influenced and interpenetrated (Kang, 2015). This interface is not only the scientific basis for enterprises, regions and countries that are in different social forms and systems to formulate relevant rules and regulations, but also a necessary and sufficient condition for obtaining the best economic benefits. In terms of Auto CAD, CAM, 3D printers as well as Big Data, new Cloud Computing technology, Internet of Things or new internet industry and AI technology, those methods have become internationally popular and important tools. However, how to adjust the industrial structure according to basic requirements of realizing the real-time analysis of the optimal micro input-output planning model and the timely analysis of the micro input-output statistical model, and carry out design and R\&D in order to better serve national economy, the real-time tabulation input-output model is helpful to point out a 
way forward.

7) According to Einstein, "Imagination is more important than knowledge". He put forward a simple hypothesis, "Creativity is equal to knowledge multiplied by curiosity and imagination". The original ideas of input-output real-time tabulation method come into being after I graduated from a "Red Guard" college and I had taken only two year basic courses before. I did not have any special talent but great curiosity and interests. In 1974, when I started to realize that input-output statistical model could solve problems of coordinated development among sectors (products) and be useful for enterprises to achieve the great economic benefits, and by being combined with linear programming, even the greater benefits could be obtained. It was not only an important tool of macro-control, but also a scientific method of overall governance. On the one hand, I was very interested in this research because of my personal experience and work experience. On the other hand, in order to promote the achievements of this scientific research, a social environment which is fair and impersonal is needed, and management personnel with integrity are required as well as recommendations of the authorities, otherwise, the achievements will be committed in vain! I eventually chose to carry out the research when I was very close making the decision (yet difficult) to give up because of all difficulties and obstructions, and I will continue till the end of my time. For the knowledge of future factory automation, information, intellectualization, Auto CAD, CAM and 3D printing, Big Data, new Cloud Computing technology, Internet of Things or new internet industry and AI, I am still studying, thinking and doing my research. Although changes and effects of AI technology for tabulation and model application have not been seen, considering $\mathrm{AI}$ is about machine learning, and a very important part of machine learning is image recognition which is to accumulate a large amount of recognition and memory of existing knowledge. According to that, one thing is certain that eventually, AI technology in the future will be able to completely substitute, even surpass the capability of human brain which now can only handle the tabulation and model application through stereotyped methods.

8) The material basis of intellectualization is by starting with single equipment automation and intellectualization of products, keeping intellectualization of key processes and substitute of key position robots as well as realizing improvements of both production efficiency and product efficiency. Internet of Things or internet need to cover not only objects of labor and means of labor as well as the integration of automated products, industrial software and services in order to boost profitability and operation efficiency of enterprises and promote digitalised transformation of business for the realization of digitalised economy, but also be opened to the information of industry market to extend client-side between all possible objects for information exchange and communication. In general, the application of enterprises' information will present a trend of integration, mobility and intellectualization. The integration of applications avoids 
the "isolated island" type of information and makes the information system become an organic entirety; the application of mobile technology breaks the limitation of time and space, multi-terminals can make access to systems anytime and anywhere which will significantly improve the cooperation efficiency. Intellectual technology is largely adopted to make the application system operation more human-oriented with better experience. Finally, with aid of information transmission, the optimal management is applied for the whole production process from orders to completion of products between enterprises and supply chains. In this case, plan, production and resources are closely combined together in a form of two-way interaction to reduce value-free activities and effectively guide the operation process of production and improve timely delivery capacity.

9) The realization of AI. As a new generation of information technology, it will present a series of far-reaching effects on innovation and development for enterprises. The competition among enterprises in the future will be the competition based on the information technology which will determine the critical competence of future enterprises. For developed countries, for example, the United States, on the basis of the three major industries which are highly modernized, it should not be difficult to establish the scientific basis of AI. It is believed that under direct leadership and guidance of International Input-Output Association, firstly, the relevant training should be carried out for personnel of high executive levels in the three major industries in order to make them pay more attention to corresponding research and development then participate in the relevant work. Secondly, for engineering enterprises who are engaged in ERP system development, future factory automation, computer science, Big data, new Cloud Computing technology, Internet of Things or new internet industry and AI, etc. and skilled workers, the relevant training should be conducted as well. On the basis of mastering the basic principle of input-output model, by combining their specialties, the relevant R\&D can be carried out. Thirdly, during the training, specialists of economics, accounting, management, law, engineering enterprises engaged in ERP system development, future factory automation, computer science, Big data, new Cloud Computing technology, Internet of Things or new internet industry and AI technology should gather together to establish a high-grade and multi-skilled R\&D team or a school, for example, International Input-Output Real-time Analysis Institute should be established in order to dedicate publishing multilingual textbooks for all grades according to the design of the cross-boundary economic management information system and provide services of applying and maintaining this information system as well as its relevant theory training and product development to universities, managers and individual users, and integrate this research result into a commercialized system application software. Fourthly, by cooperating with input-output associations of other countries and regions to carry out practical training and promotion in those countries and regions. By realizing application technology of 
ANI, the problems of tabulation and model application will be completely solved in developed countries within approximately five years. After the realization of AGI, the work which is normally done by human can be finished by AI so that tabulation and model application will be properly conducted. By realizing ASI, because it is much stronger than human intelligence, both tabulation and model application will be automatically carried out according to human expectations and even better outcomes will be achieved. In the end, all I want to say is that I hope to have my opportunity to make all this happen.

It must be pointed out that the scientific research project of the real-time input-output tabulation method which is completed by myself is a self-funded project right from the beginning. Therefore, it is a completely individual project. My wish is, as the basic content of modernized management, the "Nine Must" 【`】 linear model (it is also called Production Pioneer) will become indication, standard and measurement to observe, examine and judge whether an economy society meets the qualification of modernized management. I sincerely hope that by combining the optimal input-output planning model with automation, information, intellectualization, Big Data, new Cloud Computing technology, Internet of Things or new internet industry and AI technology, the cross-boundary economic management information system therefore constructed will become an important tool in different fields such as production, distribution, exchange and consumption in the process of reproduction. In this regard, I respectfully invite International Input-Output Association to advise the heads of governments around the world that the foundation of human society (economic basis) should be comprehensively governed and regulated, and in order to do so, as the achievement of this scientific research, the real-time input-output tabulation method must be brought into productivity as soon as possible. It is not difficult to imagine, for those manufacturers that produce all kinds of means of labours such as machinery and equipment as well as those enterprises which are engaged in Big data, new Cloud Computing technology, Internet of Things or new internet industry, AI technology, Auto CAD, CAM and 3D printers, etc., for their own survival and development, based on the basic requirements of the real-time analysis of the optimal material-based input-output planning model, the functions of their products need to be extended in order to participate the competition and take their market share. I could not have the opportunity to participate in the development of macro input-output model, nor could I use the basic data from the input-output model doing any analysis although I used to work in an enterprise for a long time and put my research outcomes into practice only twice. When I was at schools, I never had my chance studying English. After starting to work, I took some English training courses for adults and learnt some basic rules of grammar for little more than three months. For many reasons, I did not have time to continue my study. Therefore, in terms of my English comprehension, I was unable to communicate with people from other countries at the conferences of International Input-Output Association and I am fully aware of my language incapability. However, I strongly feel publishing some of 
my ideas to share with people who carry out the same undertaking as references. I have always believed that coming results will be much better than I've ever expected under the direct leadership and guidance of International Input-Output Association, in terms of following work such as R\&D, training and promotion, I believe that it will be much better implemented than I have ever expected as well as economic construction, resource conservation, prevention of corruption, scientific development and harmonious society establishment which are of common concern to mankind.

Finally, I want to give my special thanks to Mr Satoshi Inomata, the president of International Input-Output Association; Mr Wiednmann, the chairman of Planning Committee of IIOA; Mr Mahajan, the president of British IIOA; Mr Klaus, the former vice-chairman of the Regional Council of Science of the United Stated and the professor of University of Maryland for their valuable comments on my papers. I want to thank Ms Guo Yu for the translation of this article. Here, I would like to express my gratitude to them and their organizations respectively!

Due to my limitation, mistakes and shortcomings in this article are inevitably. Any criticism and correction are more than welcome!

\section{Conflicts of Interest}

The author declares no conflicts of interest regarding the publication of this paper.

\section{References}

Cai, Z., \& Xu, G. Y. (2003). AI and Its Application (4th Edition, 1st Chapter, 5th Chapter, 7th Chapter). Beijing: Tsinghua University Press.

Dong, C. Z. (2000). Analysis of Input-Output (1st Section in 2nd Chapter, 1st Section in 3rd Chapter). Beijing: Chinese Financial and Economic Publishing House.

Kang, N. (2014a). Optimal Input-Output Planning Model and Enterprise Modern Management. American Journal of Economic, 4, 240-256.

Kang, N. (2014b). Realization of Real-Time Analysis for Finance Management and SupplyDemand Chain Management. American Journal of Economics, 4, 257-272.

Kang, N. (2015). Scientific Foundation of Real-Time Tabulation of Input-Output Model and Enterprise Modern Management. American Journal of Economics, 5, 1-8.

Kang, N. (2019). An Overview of Optimal Input-Output Planning Model and Cross-Boundary Economic Management Information System. Paper I of the 27th International Input-Output Conference.

Lipson, H., \& Kueman, M. (2013). Fabricated: The New World of 3D Printing. Translated by China Centre of Information Industry Development. Beijing: China International Trust and Investment Corporation Press.

Xie, X. R. (2017). Computer Network (7th Edition, 1st Chapter). Beijing: Publishing House of Electronics Industry. 


\section{Note}

The shorter forms which are mentioned in this paper: the optimal micro input-output planning model, short for the optimal micro material-based input-output planning model and the optimal micro value-based input-output planning model; the micro input-output statistical model, short for the micro material-based input-output statistical model and the micro value-based input-output statistical model; the optimal macro input-output planning model, short for the optimal macro material-based input-output planning model and the optimal macro value-based input-output planning model; the macro input-output statistical model, short for the macro material-based input-output statistical model and the macro value-based input-output statistical model; the optimal input-output planning model, short for the optimal micro input-output planning model and the optimal macro input-output planning model; real-time analysis of the optimal input-output planning model, short for real-time analysis of the optimal micro input-output planning model and timely analysis of the micro input-output statistical model as well as real-time analysis of the optimal macro input-output planning model and timely analysis of the macro input-output statistical model; the scientific foundation of the optimal input-output planning model and AI, short for the scientific foundation of the optimal micro input-output planning model along with the micro input-output statistical model and AI as well as of the optimal macro input-output planning model along with the macro input-output statistical model and AI; the scientific foundation of AI, short for the scientific foundation of real-time input-output tabulation method and AI; cross-boundary economic management information system, short for real-time input-output tabulation method and cross-boundary economic management information system. 
[*] The Basic Content of the "Nine-Must"-Production Pioneer of Linear Model in Enterprise Modern Management

1) Why must it be necessary to draw up the production and management plans with the optimal input-output planning model?

2) Why must it be necessary to draw up inventory strategies with the input-occupancy-output model?

3) Why must it be necessary to establish the grey input-output model to study the connection between input and output of grey factor?

4) Why must it be necessary to establish the dynamic input-output model to carry out dynamic analysis?

5) Why must it be necessary to realize the combination and connection between the optimal input-output planning model and the enterprise resource planning (ERP), lean production, agile manufacturing, etc.?

6) Why must it be necessary to realize the combination and connection between the optimal input-output planning model and the total-factor productivity (TFP), target management and other modern management methods?

7) Why must it be necessary to realize the real-time analysis for the optimal input-output planning model and the finance management?

8) Why must it be necessary to realize the real-time analysis for the optimal input-output planning model and the supply-demand chain management?

9) Why must it be necessary to use the optimal input-output planning model to conduct the analysis of policy? 